\title{
TENDENCIAS DEFORMANTES Y PARATEXTOS EN LA TRADUCCIÓN AL INGLÉS DE HUASIPUNGO, DE JORGE ICAZA
}

\section{TEXT DEFORMATION AND PARATEXTS IN THE ENGLISH TRANSLATION OF HUASIPUNGO, BY JORGE ICAZA}

\section{María del Pilar Cobo González Roberto Bein**}

\section{RESUMEN}

Huasipungo, de Jorge Icaza, es quizá la novela ecuatoriana más reconocida en el mundo. Esta obra, cuya primera versión fue escrita en 1934, refleja el sufrimiento de los indígenas huasipungueros ante los maltratos de los mestizos. Si bien Icaza utiliza varias estrategias para reflejar el sufrimiento de los indígenas y plasmar su forma de vida, el uso del lenguaje es la más efectiva, pues, mediante este, caracterizado por una marcada influencia del quichua andino, pretende dar voz a quienes no la tienen. Esta estrategia presenta una dificultad en el momento del traducir la novela a otros idiomas. En este trabajo se analizarán los rasgos que caracterizan a la traducción al inglés de Huasipungo (titulada The Villagers), realizada por Bernard Dulsey y publicada en 1964. Esta traducción se basa en la segunda versión de la novela, de 1953, pues Icaza la revisó y reformuló la prosa. Dulsey recurrió a varias estrategias que le permitieron mantener esta esencia. Se analizarán los paratextos de la traducción (el título, la introducción y el glosario) para entender cómo contribuyen para que el lector angloparlante se acerque a la problemática del indígena ecuatoriano de la década de los años treinta. No obstante, muchas características lingüísticas y culturales de los indígenas se pierden al traducirse al inglés. Estas pérdidas serán analizadas mediante una revisión de algunas de las tendencias deformantes que anota Berman en su texto 'La analítica de la traducción y la problemática de la deformación' (1999).

Palabras claves: Huasipungo; Jorge Icaza; deformación; traducción.

\section{ABSTRACT}

Huasipungo, by Jorge Icaza, is perhaps the most recognized Ecuadorian novel in the world. This novel, whose first version was written in 1934, reflects the suffering of the indigenous buasipungueros before the mistreatment of the mestizos. Although Icaza uses several strategies to reflect the suffering of indigenous people and their way of life, the use of language is the most effective, because, through this, characterized by a marked influence of Andean Quichua, it seeks to give voice to those who do not. This strategy presents a difficulty at the time of translating the novel into other languages.

\footnotetext{
* Universidad de Buenos Aires, Buenos Aires, Argentina. pilicobo@gmail.com

** Universidad de Buenos Aires, Buenos Aires, Argentina. roberto.bein@gmail.com
} 
In this paper we will analyze the features that characterize Huasipungo's English translation (entitled The Villagers), by Bernard Dulsey and published in 1964. This translation is based on the second version of the novel, from 1953, as Icaza reviewed it and reformulated prose. Dulsey resorted to several strategies that allowed him to maintain this essence. The paratexts of the translation (the title, the introduction and the glossary) will be analyzed to understand how they contribute so that the English-speaking reader approaches the problematic of the Ecuadorian indigenous of the decade of the thirties. However, many linguistic and cultural characteristics of indigenous people are lost when translated into English. These losses will be analyzed through a review of some of the deforming tendencies that Berman notes in his text 'L’analytique de la traduction et la systématique de la déformation' (1999).

Keywords: Huasipungo; Jorge Icaza; deformation; translation.

\section{INTRODUCCIÓN}

Huasipungo, de Jorge Icaza, es quizá la novela ecuatoriana más reconocida en el mundo. Esta obra, cuya primera versión fue escrita en 1934, refleja el sufrimiento de los indígenas huasipungueros ante los maltratos de los mestizos, los latifundistas, la Iglesia y el poder político. Huasipungo es un ejemplo del relato indigenista, que ha sido ubicado dentro del realismo social. Si bien Icaza utiliza varias estrategias para reflejar el sufrimiento de los indígenas y plasmar su forma de vida, el uso del lenguaje es la más efectiva, pues, mediante este, caracterizado por una marcada influencia del quichua ${ }^{1}$ andino, pretende dar voz a quienes no la tienen en la sociedad. Esta estrategia, sin embargo, presenta una dificultad en el momento del traducir la novela a otros idiomas.

En este trabajo se analizarán los rasgos que caracterizan a la traducción al inglés de Huasipungo (titulada The Villagers), realizada por Bernard Dulsey y publicada por la Universidad de Southern Illinois en 1964. Esta traducción se basa en la segunda versión de la novela, de 1953, pues Icaza la revisó y reformuló la prosa. Si bien se eliminan algunos rasgos del habla indígena en esta versión, considerada por el autor mejor que la de 1934, la esencia lingüística y cultural se mantiene. En el caso de la traducción, Dulsey recurrió a varias estrategias que le permitieron mantener esta esencia. En este caso se analizarán los paratextos de la traducción (el título, la introducción y el glosario) para entender cómo contribuyen para que el lector angloparlante se acerque a la problemática del indígena ecuatoriano de la década de los años treinta. No obstante, muchas características lingüísticas y culturales de los indígenas se pierden al traducirse al inglés. Estas pérdidas serán analizadas mediante

1. En este texto utilizaré la palabra 'quichua' en lugar de 'quechua', pues la primera es la variedad que se habla en Ecuador. No obstante, ciertos autores citados se refieren a 'quechua'. 
una revisión de algunas de las tendencias deformantes que anota Berman en su texto ‘La analítica de la traducción y la problemática de la deformación’ (1999).

\section{EL INDIGENISMO EN HUASIPUNGO}

Antes de analizar los rasgos del habla indígena en Huasipungo y cómo estos fueron traducidos al inglés por Bernard Dulsey, es importante revisar algunas características generales de la novela y la inscripción de esta en el indigenismo. En primer lugar, el título de la novela es una palabra compuesta quichua: buasi, casa, y pungo, puerta; es decir, se traduce literalmente como puerta de la casa. No obstante, el huasipungo se refiere a la parcela de tierra que los latifundistas entregaban a los indígenas (generalmente en los terrenos menos fértiles) para que los cultivaran. A cambio de estos terrenos, los indígenas (considerados propiedad de los terratenientes) debían trabajar en las haciendas. La práctica del huasipungo fue muy común en Ecuador en las primeras décadas del siglo pasado, hasta la instauración de la Reforma Agraria, a finales de los años sesenta e inicios de los setenta.

La trama de la novela de Icaza se ubica en la primera década del siglo XX, cuando la práctica del huasipungo era considerada normal. Ecuador se encontraba en una época en la que económicamente dominaban los terratenientes. Antonio Sacoto, en su texto 'Jorge Icaza: el indigenismo ecuatoriano', explica la situación que vivía el indio en esa época:

\footnotetext{
El indio era propiedad del huasipungo, carecía de toda libertad y ni siquiera era dueño de su honor, de ahí que los latifundistas y sus hijos creían que había que poseer a las indias por fuerza y por derecho. Al indio se le había degradado, estropeado y humillado al punto que apenas podía éste levantar los ojos al patrón, apenas podía balbucir unas palabras incoherentes entre el quechua vernáculo y el español aprendido en medias frases. Era insolente si se permitía hablar claro. Atrevido si se permitía razonar. Peligroso si era diligente. Tal era la triste y macabra realidad del indio ecuatoriano en los años diez (1991, p. 254).
}

Sacoto señala, asimismo, que los latifundistas manejaban la economía del país, pues esta era principalmente agraria, además influían en la política nacional y tenían una relación muy cercana con la Iglesia (que también era una de las grandes propietarias de la tierra). Ante esta situación, la desigualdad era patente: para el indígena era imposible rebelarse contra el statu quo, pues había sido víctima de una dominación constante desde la época de la Colonia.

Si bien la historia de la novela transcurre en la década de los años diez del siglo pasado, Icaza la escribe en los años treinta. Él es uno de los mayores representantes del realismo social en Ecuador $y$, sobre todo, de la corriente indigenista. La 
generación literaria de los años treinta en Ecuador se caracteriza por un grupo de escritores "de tónica social, con un afán de demostrar que el mundo está mal hecho, que las cosas deben cambiar, que se debe denunciar el elemento maligno, perverso, ignorantón" (SACOTO, 1991, p. 255). La crítica social y la denuncia de la desigualdad son las principales intenciones de este grupo de escritores, que intenta marcar una clara diferencia con la escritura que predominaba en las décadas anteriores, "señorialoligárquica" y "que nada tenía de propiamente nacional", según lo señala Agustín Cueva (1978, p. 30).

En su juventud, precisamente en la década de los años diez, Icaza vivió en la hacienda de su tío y pudo ver cómo se maltrataba a los indígenas. Ahí conoció ese mundo en el que el indígena era cosificado e ignorado, no solo por el 'gran patrón, su mercé' (como se refiere al latifundista en su obra), dueño absoluto de su vida, sino también por el mestizo, el cholo. Sin embargo, durante las décadas que median entre esta vivencia de Icaza y la publicación de Huasipungo, la situación social del indígena no varió mucho, por eso Icaza plasmó en su obra la situación de su tiempo y la que vivió en su época. Sacoto se refiere así a los personajes indígenas de Icaza:

El indio de Icaza es aquel que nace sobre cueros, entre perros y cuyes, al calor de un fogón, en medio del huasipungo, y vive hundido en una semi-inconsciencia de miseria y abandono, sufre todos los estragos de la esclavitud, de la explotación colectiva, y su visión del mundo no rebasa la tierra que trabaja y cuyo fruto le es vedado y al cabo de los años muere lleno de taras (1991, p. 256).

En una entrevista personal con Bernard Dulsey, el traductor de Icaza al inglés y estudioso de Latinoamérica, el autor confiesa que su intención con Huasipungo era que esta novela "con su protesta tremenda, contribuya -pequeño aporte sentimental de la literatura en las masas- a redimir al huasipunguero. A hacerle conocer en su dolor, en su soledad, en su desesperanza. El indio en el Ecuador sigue en la misma situación" (1961, p. 99). En estas frases se vislumbra lo que se quiere demostrar en Huasipungo: un relato descarnado de la situación real del indígena. Por esta razón, se presenta a los personajes sin ningún tipo de romanticismo, desligados completamente de los relatos naturalistas del siglo XIX que lo representaban como el buen salvaje.

Una de las maneras de demostrar esta realidad de los indígenas en el Ecuador de las primeras décadas del siglo XX es precisamente darles voz, permitirles hablar en su lengua, que el texto literario funcione como un mediador entre la realidad y los lectores. Por esta razón, el idioma quichua, la lengua originaria de los indígenas, funciona como una marca de identidad. Mediante esta lengua, que se mezcla a menudo con el español, Icaza da personalidad a sus personajes. Aparte de la lengua, 
en Huasipungo encontramos varias alusiones a las costumbres y a la vida real de los indígenas en los Andes ecuatorianos. No obstante, como lo afirma Dulsey, este discurso, salpicado por palabras y rasgos culturales, puede significar un obstáculo lingüístico para el lector angloparlante (1961, p. 100).

\section{LAS DOS VERSIONES DE HUASIPUNGO Y SUS TRADUCCIONES AL INGLÉS}

Antes de continuar con el análisis de las versiones y las traducciones de Huasipungo al inglés, resumiré brevemente la novela, para facilitar la comprensión del lector. La historia empieza cuando el hacendado Alfonso Pereira se encuentra agobiado por las deudas (cuyo acreedor más fuerte es su tío Julio) y por una gran vergüenza familiar: su hija Rosita ha quedado embarazada de un cholo. Mientras camina por la calle pensando en la manera de solucionar, sobre todo, este problema de honor, su tío Julio lo sorprende y lo invita a conversar. La propuesta del tío Julio significará la gran solución a sus problemas. El tío quiere hacer negocios con 'los gringos' para explotar madera (que en realidad es petróleo) y, para esto, necesitarán construir una carretera que pasará por la hacienda Tomachi, de propiedad de los Pereira. La construcción de la carretera implicará comprar terrenos cercanos a la hacienda y expulsar a los indígenas de sus huasipungos. La labor de Alfonso será supervisar que todo esto ocurra correctamente, pues lo estadounidenses pondrán el dinero. Esta no solo será una gran salida para subsanar las deudas, sino la gran oportunidad para limpiar el honor de la familia: Alfonso viajará con su hija y su esposa, y cuando Rosita dé a luz les dirá a todos que el hijo es de su esposa, Blanquita.

Ya a partir de la narración del viaje desde la ciudad a Tomachi se evidencia cómo los indígenas sirven de animales de carga, pues, al no poder usar las mulas debido al mal clima, los indios deben cargar a los patrones. Aquí aparece la figura de Andrés Chiliquinga, el principal personaje indígena. Al llegar a la hacienda, Alfonso comienza su cometido: compra las tierras aledañas y empieza la construcción de la carretera, para la cual utilizará como mano de obra a los indígenas de sus tierras, quienes se ven abocados a un trabajo agotador en las peores condiciones. Para mitigar cualquier molestia, se les engaña con ingentes cantidades de alcohol, provistas por la esposa del teniente político, y se los coacciona mediante el látigo del mayordomo Policarpio. Debido a la urgencia de terminar la carretera y contar con los indios para preparar el camino, Alfonso prohíbe limpiar el río (tarea anual que realizan para evitar inundaciones) y, por esto, una creciente termina con los huasipungos de los indígenas, una coincidencia oportuna para los planes de Pereira. 
Luego de perder sus tierras, la situación de los indígenas se vuelve peor: sin huasipungos en los que cosechar, las familias empiezan a morir de hambre, y el ambicioso terrateniente niega a sus indios cualquier ayuda. Debido a la hambruna, un grupo de indígenas decide robar la carne de un toro que había muerto y les habían obligado a enterrar. Esta carne dañada causa la muerte de Cunshi, la compañera de Andrés Chiliquinga. Además, debido a que perdieron sus casas, los indígenas se ubican en las lomas, de donde Pereira intenta desalojarlos con la ayuda de la Policía. En este momento Chiliquinga convoca, con el toque del cuerno, a la lucha por las tierras, al grito de "Nucanchic huasipungo" (nuestro huasipungo). El dolor y la desesperación por perder sus tierras milenarias hacen a los indígenas despertarse.

Como mencioné, existen dos versiones de Huasipungo: la de 1934 y la de 1953. En una carta personal dirigida a Ross Larson, Icaza explica:

Hice la revisión de la novela llevado de un deseo de darle mayor claridad para el mundo internacional. Al escribir la novela no creí que ella pudiera tomar un vuelo hacia todas las latitudes del mundo. Mi afán era regional -que sirviera de mensaje y emoción a las gentes de mi pueblo para la resolución de sus problemas. Pero la dificultad de las traducciones en los giros y en las palabras se hacía cada vez más infranqueable. En tal virtud me vi, casi obligado, a la revisión. (1965, p. 210).

Es importante notar que Icaza revisó la obra para facilitar las traducciones. Esto se puede apreciar, por ejemplo, en el caso de las dos traducciones de Huasipungo al inglés. La primera, que conservó el título original Huasipungo, se basó en la edición de 1934, y fue traducida por Mervyn Savill en 1952 y publicada en Inglaterra en 1962. La segunda versión, traducida por Bernard Dulsey y publicada en EE.UU. en 1964, se basó en la revisión de 1953 y se publicó bajo el título de The Villagers. Si bien las versiones de 1934 y 1953 cuentan la misma historia, hay notables diferencias entre ellas; de hecho, por ejemplo, en la segunda se da más voz a los indígenas y se cambian numerosas narraciones por diálogos. Cecilia Mafla apunta otros cambios: "Otra diferencia marcada en la segunda versión es que el registro lingüístico del narrador es generalmente más alto y el habla del indígena es menos marcada que en la de 1934. Esto disminuye la dificultad para Dulsey, el traductor de la segunda versión" (p. 2004, 15).

En una revisión de las traducciones de Icaza al francés, Olga Caro (1995) se refiere a que la segunda versión de la novela no solo representa un salto estético sino también ideológico, y cita al lingüista Renaud Richard, que asegura que "el enfoque clasista o la 'terminología marxista' de 1934 evoluciona hacia una expresión que se refiere más a la realidad hispanoamericana [...] patentiza la presencia de un sinnúmero de retoques y añadidos, muchos de los cuales inician o profundizan el 
aspecto psicosociológico de estos personajes" (cit. en CARO 1995,16). Precisamente una de las maneras de profundizar en estos aspectos psico-sociológicos, en el caso de los personajes indígenas de Huasipungo, es recurrir a las voces quichuas. Mediante estas, se diferencia su voz de las voces de los dominadores.

Según Dirk Delabastita, incluir las variedades lingüísticas dentro de un texto "tiene como misión principal, no solo la representación o evocación de una realidad externa al texto sino la modificación y reconfiguración de esas realidades a partir de un propósito ideológico determinado en el texto literario" (cit. en SPOTURNO 2013 , p. 1). Precisamente, la intención de esta inclusión del quichua dentro de la obra de Icaza no es meramente literaria, es también ideológica y sociológica, es una manera de comprometerse con la lucha de los oprimidos, como lo anota Vetrano en relación con los novelistas indigenistas: "fue natural y lógico [...] que los novelistas expresaran en sus obras la preocupación y la compasión por las masas oprimidas y que intentaran, por medio de su habilidad literaria, remediar las condiciones socioeconómicas que avasallaban al indio y al mestizo" (1974, p. 104).

Ya que la intención de Icaza no solo es literaria sino también ideológica, es importante tomar en cuenta la inclusión del quichua hablado por los indígenas, un quichua matizado por expresiones del español. Este, como anotan Mafla (2004) y Vetrano (1974), es un rasgo que debe tomarse en cuenta en las traducciones, y que representa una dificultad para el traductor. En la versión de 1953 la voz del indígena se hace más evidente, pues se incluyen numerosos diálogos. No obstante, en esta última la variedad que habla el indígena es menos marcada que la de la versión de 1934.

Vetrano señala algunas de las características del quichua de la Sierra ecuatoriana que se evidencian en las voces indígenas de Huasipungo. Estas características luego son retomadas por Mafla. A continuación, enumeraré muy brevemente estos rasgos.

1. Las vocales españolas o y e no forman parte del sistema fonológico del quichua ecuatoriano. Estas vocales son reemplazadas por los sonidos /u/ e /i/, respectivamente. En este aspecto, es interesante notar que Icaza fue más estricto en la primera versión, mientras que en la segunda optó por acercarse un poco más a los sonidos del español. Veamos, por ejemplo, la siguiente frase: "Utrus añus qui venga tan guañucta himus di cumer" (ICAZA, 1934, p. 97) y "Otrus añus que vengan tan, guañucta hemus de cumer" (ICAZA, 1963, p. 176).

2. "El fonema /f/ (labiodental fricativa sorda; bilabial en el español del Ecuador), ante el diptongo /ue/, se convierte en el sonido uvular vibrante /h/, representado en la ortografía por la j" (Vetrano 1974, 112). Por ejemplo, juerte en lugar de fuerte. 
3. Se convierte en palatal fricativa sonora /ž/ al sonido que representa el dígrafo 11 . Por ejemplo: cashadu (por callado) o gashinita (por gallinita).

4. Cambios esporádicos propios del habla del indígena de la Sierra, como aféresis, apócopes, síncopes y metátesis.

5. Asimismo, se diptongan algunas palabras, precisamente por la predominancia de las vocales /i/ y de la /u/.

6. Cambios en la acentuación.

Aparte de estas características del habla indígena, también se incluyen palabras quichuas dentro del texto, algunas de las cuales ya se encuentran incorporadas al habla coloquial ecuatoriana. Por ejemplo, en el episodio del lamento de Andrés Chiliquinga por la muerte de Cunshi, podemos notar algunas:

"- Guagua² tan shorando está.

- $\mathrm{Ashcu}^{3}$ tan shorando está.

- Huaira ${ }^{4}$ tan shorando está" (ICAZA, 1964, p. 176).

Otro aspecto importante que caracteriza al habla de los indígenas es el uso de los diminutivos, que tiene un sentido afectuoso en el habla de la Sierra ecuatoriana. En este sentido, no es solo característico de los indígenas; no obstante, en el caso de Huasipungo, también se usan para expresar el respeto del indígena hacia los terratenientes, los mayordomos o el sacerdote, considerados en una posición social más alta. Por ejemplo, es muy frecuente el uso de la palabra patroncitu o amitu.

Mafla analiza otros aspectos que deben tomarse en cuenta referentes al quichua. Entre ellos se encuentran el uso del morfema quichua ca y su variante ga. Este morfema, explica, "funciona como un marcador del sujeto en la oración, o para dar énfasis en lo que se está hablando" (MAFLA, 2004, p. 73). Este morfema, añade Mafla, no es exclusivo de los indígenas en la novela, sino también es usado por los cholos. No obstante, en el glosario que incluye Icaza en la versión de 1953, se explica que esta partícula "solo sirve para dar fuerza a la frase" (p. 216). Dulsey, en el glosario de la traducción, solo incluye ga, y lo define igual que Icaza: "An expression used just to give emphasis to a phrase" (p. 221).

Asimismo, Mafla anota otras características, como la repetición de palabras, la falta de concordancia en el género, falta de artículos, falta de objeto directo,

2.Niño. Esta palabra forma parte del habla coloquial ecuatoriana.

3. Perro.

4.Viento. Es interesante, además, notar que esta línea fue introducida en la versión de 1953, pues no consta en la versión de 1934. 
la alternancia del trato formal e informal de los indígenas hacia las autoridades, entre otros. A continuación, revisaré algunas de las características de la traducción de Bernard Dulsey al inglés, y algunas dificultades con las que se ha enfrentado durante la traducción. En la última parte de este análisis, revisaré las estrategias y las deformaciones que caracterizan a esta traducción.

\section{LA TRADUCCIÓN AL INGLÉS DE BERNARD DULSEY}

Como he mencionado, Jorge Icaza consideraba a la versión corregida de Huasipungo en 1953 la mejor de las dos. Para escribir esta versión, tomó en cuenta las dificultades que el texto de 1934 había generado a las traducciones. Para la traducción de la segunda versión, Icaza se contactó con Bernard Dulsey, con quien trabajó muy de cerca durante tres años. Dulsey fue profesor de la Universidad de Kansas, y un estudioso de la cultura y de la literatura de Latinoamérica. J. Cary Davis, editor de la traducción de Huasipungo al inglés, bajo el título de The Villagers, comenta en el prólogo que Dulsey, como buen amigo de Icaza y conocedor de cada aspecto de la vida y obra del autor, es la persona idónea para interpretar al público estadounidense las características esenciales del mensaje icaciano. Añade también que Dulsey revisó cuidadosamente con Icaza aquellas expresiones que parecían tener una connotación especial.

Asimismo, en el prefacio de The Villagers, Icaza menciona "el profundo sentido humanista, la calidad moral y el singular talento" de su amigo Dulsey, que exitosamente "ha sabido distinguir dónde se encuentra la falsedad reaccionaria de los jefes políticos, los terratenientes, los líderes militares y los oligarcas" y "de dónde emana la auténtica fuerza creativa, cultural y emocional de la gran ciudad y las mayorías rurales" (ICAZA, 1964)..$^{5}$

En la introducción a The Villagers, Dulsey da cuenta del esfuerzo que ha realizado al tratar de preservar la poesía y el simbolismo del español en su versión en inglés. Habla de las sorprendentes descripciones del hombre y la naturaleza, y cita ejemplos como la descripción del pueblo de Tomachi, la inundación o el lamento de Andrés Chiliquinga por Cunshi. Dulsey habla también acerca de la dificultad que puede significar para los lectores angloparlantes el lenguaje de los personajes de Icaza, salpicado de quichuismos.

Beata Fabjańska-Potapczuk, en el texto 'El concepto del indigenismo y las dificultades en la traducción al idioma polaco', habla del problema que representa

5. La traducción es mía. 
traducir el 'español modificado' por los autores indigenistas, con influencias del quechua. Plantea así los interrogantes con los que se encuentra el traductor:

\begin{abstract}
¿Cómo cruzar la distancia entre el "mundo indio" y nuestro mundo, aún alejado de aquel mundo blanco latinoamericano? ¿Cómo transponer la sensibilidad y el mundo indígena a otro mundo que en toda su historia no tuvo nada parecido? En este momento el traductor no sólo se convierte en el segundo autor del texto, sino en el tercer autor. No puede basarse solamente en las nociones y léxico del texto original, sino que se debe conocer este "tercer mundo", el más profundamente escondido, punto de partida para la obra. Debe tener en cuenta también que su receptor es, por lo general, un lector que no posee conciencia de cómo es este "tercer mundo" (2015, p. 79).
\end{abstract}

Aunque el texto de Fabjańska-Potapczuk se refiere a la traducción al polaco, bien pueden aplicarse estas disyuntivas a las traducciones a otros idiomas, como el inglés. Si bien Dulsey es un gran conocedor de la cultura hispanoamericana, trasladar el mundo indígena a su lengua no resulta sencillo; más aún si tomamos en cuenta que su intención no solo era mostrar "la miseria del indígena de la Sierra ecuatoriana, sino también (y quizá más importante), dar un ejemplo de la literatura ecuatoriana" (MAFLA 2004, 40). Por otro lado, el reto de Dulsey es lograr que esta esencia no se pierda en el camino y llegue a la cultura meta, que se trate de una traducción adecuada, pero también aceptable. ${ }^{6}$ Para esto, en su traducción se vale, por ejemplo, de los paratextos. A continuación revisaré brevemente tres de estos: el título, la introducción y el glosario.

\title{
LOS PARATEXTOS DE LA TRADUCCIÓN DE DULSEY
}

Al analizar la traducción de Huasipungo al alemán, Susana Romano indica que "el traductor se vuelve visible especialmente en el aparato paratextual en el cual se autopresenta y representa, y de este modo se convierte en un vehículo de transferencia intercultural" (2009, p. 139). En el caso de la traducción al inglés de Dulsey, esto es evidente, pues en los paratextos reconocemos al traductor y a su relación con Icaza, su libro y la realidad latinoamericana. En el caso de los paratextos que analizaré, Dulsey toma decisiones en relación con la adecuación y la aceptabilidad de su traducción.

En primer lugar, es importante tomar en cuenta el título que se ha elegido para esta traducción: The Villagers. Si bien Dulsey no se refiere a este aspecto en ninguno de los textos referentes a Huasipungo que he consultado, es evidente que esta es una decisión tomada en pos de la aceptabilidad de la traducción en el

6. Adecuación y aceptabilidad en el sentido que les da Toury (1995). 
público estadounidense. En el prólogo, el editor J. Cary Davis establece: "The title chosen for this edition, The Villagers, was thought to convey most adequately the essential meaning of the original Qhechuan term Huasipungo used by the author". De esta frase podemos colegir que se ha tratado de una decisión editorial, pues el título original, que además es una palabra quichua, no dice nada a los lectores estadounidenses. Sin embargo, este título tiene una gran carga cultural, que no se conserva en la traducción, incluso porque el título escogido para la traducción de Dulsey se refiere a personas, mientras que el título original se refiere a una 'institución' con un significado cultural y social muy fuerte.

Mafla, citando a Catford, sostiene que el caso del título es una "palabra cultural intraducible" (2004, p. 61), pues no existe una equivalencia en la lengua meta. Catford habla de "intraductibilidad cultural" para referirse a un rasgo situacional, funcionalmente relevante en la lengua fuente que está completamente ausente en la cultura de la lengua meta $(1965$, p. 99). Por este motivo, seguramente, se optó por The Villagers en lugar del préstamo directo, como se hace en la traducción de Savill, de la primera versión del libro. Si bien el título ha sido cambiado en pos de la aceptabilidad, y debido a su intraductibilidad cultural, el título original consta entre paréntesis en la portada, bajo The Villagers. Quizá esta fue una estrategia de adecuación, sobre todo para conservar de alguna forma el título original.

Otro paratexto que es importante en la traducción de Dulsey es la Introducción. Aunque como el mismo Dulsey lo aclara en una nota de pie de página, la mayoría de los datos de esta introducción son tomados de un texto previo publicado en la revista Hispania, ${ }^{7}$ existen algunos datos referentes a la traducción en sí. En primer lugar, en otro pie de página, Dulsey anuncia que no se basa en la primera edición de Huasipungo sino la segunda, de 1953. Y anota: "Icaza himself requested that I make my translation from the expanded 1953 version, which he considered superior to his original work" (ix). Al final de la Introducción, también agradece a Icaza por su generosa cooperación durante tres años en responder sus dudas en relación con cuestiones léxicas y culturales.

En la Introducción de Dulsey, me parece importante destacar dos frases: "There is much unusual imagery in Spanish, which I have made every effort to preserve in the English version" $(\mathrm{x}) \mathrm{y}$ "Their speech [de los personajes indígenas de Icaza] is larded with Qhechuan terms which often raise linguistic obstacles for the

7. 'Jorge Icaza and his Ecuador', publicado en Hispania, en marzo de 1961. Si se revisa este texto, se puede notar que, prácticamente, ambos dicen lo mismo respecto de Icaza y su obra. Incluso se usan las mismas comparaciones y las mismas referencias (solo que en el texto de Hispania hay muchas citas en español, mientras que en esta introducción todo se ha traducido al inglés). 
North American readers of Spanish" (xii). Estas dos frases resultan claves porque aluden a la relación entre la lengua fuente y la lengua meta, y dan cuenta de los esfuerzos de adecuación y aceptabilidad a los que se ve abocado el traductor. En la primera frase se puede notar que para Dulsey es importante mantener la adecuación, con el fin de que los lectores de la traducción puedan percibir ciertos rasgos de la lengua fuente. En la segunda frase se puede notar que el traductor tiene conciencia de la dificultad que representa el quichua para los lectores angloparlantes. Sin embargo, pese a la conciencia de esta dificultad, es interesante cómo Dulsey recurre constantemente a préstamos del quichua en su traducción.

Con respecto a los préstamos del quichua, Dulsey explica en el Glosario la razón para mantener la lengua original: "We thought it proper and even essential to maintain this words in original tongues for without them a good deal of the Andean flavor of the original would be lost in the translation" $(1964,219)$. Esta intención de mantener el sabor andino demuestra una estrategia de adecuación. Sin embargo, para que exista aceptabilidad, se incluye el Glosario. En este paratexto, el traductor define varias palabras que ha mantenido del español y del quichua (en especial de este último), y que son importantes para entender el contexto cultural y social en el que se desarrolla la novela. Y también para entender la intención de Icaza al escribir Huasipungo.

En la introducción del Glosario, Dulsey se dirige a quienes no hablan español ni quichua, e indica, por un lado, que hay palabras que pueden encontrarse con una escritura distinta (en el caso de amo/amu), debido a las características del habla indígena. Por otro lado, hace una salvedad respecto de los diminutivos, y anota que en varios pasajes se encontrará este tipo de palabras, pero indica que las describirá solo bajo la palabra original. Pese a que indica que solo incluye los diminutivos taiticu y taitiquitu (de taita, padre), también incluye longuito ${ }^{8}$ y shunguitico. ${ }^{9}$ Cabe anotar que, en la versión de Icaza de 1953, el autor también incluye un glosario en el que define varias palabras del quichua. La mayoría de palabras definidas por Dulsey se encuentran en el glosario de Icaza y, cuando esto sucede, las definiciones son una traducción del original.

\section{TENDENCIAS DEFORMANTES EN LA TRADUCCIÓN DE DULSEY}

Si bien los paratextos que introduce Dulsey en su traducción de Huasipungo son bastante acertados, el hecho de que la prosa de Icaza cuente con quichuismos y

8. "Diminutive of longo; often used to show affection" (1964, p. 221).

9. "Diminutive of shungo; affectionaly used" (1964, p. 222). 
características propias del habla indígena de la Sierra genera que el traductor deba tomar algunas decisiones que pueden hacer que se pierda un poco la esencia del texto y la intención del autor de mostrar la realidad indígena.

Al hablar sobre la prosa literaria, Berman anota que esta se caracteriza "por el hecho de que capta, condensa y entremezcla todo el espacio polilingüístico de una comunidad. Moviliza y activa la totalidad de las 'lenguas' coexistentes en una lengua" (1999, p. 2). Precisamente esto sucede en la obra de Icaza, pues en ella se mezclan varias lenguas, siguiendo a Berman. Podemos ubicar la lengua de los terratenientes y del cura (nobles y blancos); la del mayordomo y el teniente político (cholos, mestizos), y la de los indígenas. Son tres variedades que se mezclan en la obra de Icaza y que se comunican entre ellas. Los cholos y los indígenas de Icaza incluyen en su habla voces quichuas y cambios en la pronunciación de palabras del español, como ya hemos visto. En esta variedad de lenguas está la riqueza de Huasipungo; riqueza que, sin embargo, no logra distinguirse del todo en la traducción del inglés.

Berman habla también de varias tendencias deformantes que se desprenden del intento de traducir la informidad de la prosa, generada, precisamente, por esta proliferación de lenguas. Este autor menciona 13 deformaciones que pueden estar presentes en las traducciones. ${ }^{10}$ En este apartado revisaré algunas de estas. Me basaré, sobre todo, en el fragmento de Huasipungo referente a la muerte de Cunshi y al lamento de Andrés Chiliquinga ante este hecho (ver Anexo). He tomado este fragmento de la novela porque considero que en este se evidencia la mezcla entre el quichua y el español en el habla indígena, y también porque este lamento es parte del chasquibay de Cunshi. El chasquibay es una costumbre indígena, en la que los deudos del difunto se lamentan por turnos, acompañados de música. Icaza lo define en su glosario como "lamentación de los deudos ante un cadáver" (1953, p. 217). En la manera de tratar esta costumbre se pueden evidenciar varias tendencias en las que ha incurrido Dulsey en su traducción.

En primer lugar, considero que en la traducción de Dulsey se da, principalmente, la tendencia que Berman denomina "destrucción o la exotización de las redes lingüísticas vernáculas". Al tratar esta tendencia deformante, Berman anota que "la prosa puede plantearse como fin explícito retomar la oralidad vernácula" (1999, p. 9), y esto sucede en Huasipungo. Icaza reproduce el habla indígena no

10. Estas son las siguientes: la racionalización, la clarificación, el alargamiento, el ennoblecimiento y la vulgarización, el empobrecimiento cualitativo, el empobrecimiento cuantitativo, la homogeneización, la destrucción de los ritmos, la destrucción de las redes de significantes subyacentes, la destrucción de los sistematismos textuales, la destrucción (o exotización) de las redes lingüísticas vernáculas, la destrucción de las locuciones e idiotismos, la supresión de las superposiciones de lenguas. 
porque se trata de algo exótico, que da 'color' a su texto, sino porque lo considera un compromiso social. En la traducción de Dulsey, esta oralidad se suprime, adquiere un carácter homogéneo (otra de las tendencias que anota Berman).

Eso sucede, por ejemplo, en el lamento de Andrés Chiliquinga, en el cual se repiten constantemente las expresiones "Ay Cunshi, sha" y "Ay bonitica, sha", que Dulsey traduce como "Ay, Cunshi, sha - gone forever" y "Ay, bonitica - lovely one, gone forever". Si bien la primera línea repite la palabra "sha", en las otras ocasiones la suprime. Esta expresión, "sha" es una expresión de cariño en el quichua que no equivale, tampoco, al "lovely one" de la segunda línea. En el resto de ocasiones en las que se traduce esta expresión, Dulsey elimina "sha" y "lovely one", y solo escribe "gone forever", que es una expresión que no corresponde a "sha" y suprime la textualidad vernácula.

Así mismo, Berman anota que dentro de esta tendencia puede ocurrir que se supriman los diminutivos. Esto es algo evidente en la traducción de Dulsey. Si bien él menciona en el glosario que los diminutivos son frecuentes en el quichua y que en ese apartado solo constarán palabras sin este rasgo, me parece que hubiera sido más adecuado aumentar palabras en el glosario que hacer ciertas traducciones. Por ejemplo, esto sucede con la palabra "cuicitu", que en inglés se traduce por "little guinea pig", y varios otros diminutivos, que son propios del habla quichua. Veamos, por ejemplo, este caso:

\begin{tabular}{|l|l|}
\hline $\begin{array}{l}\text { Ya no teniendu taiticu Andrés ni maicitu, ni } \\
\text { mishoquito, ni zambitu. (1953, p. 175) }\end{array}$ & $\begin{array}{l}\text { Taitucu Andrés won't have no more corn, no } \\
\text { more potatoes, no more pumpkins. (1964, p. } \\
179)\end{array}$ \\
\hline
\end{tabular}

En esta frase, se puede ver cómo se han suprimido los diminutivos, y cómo esto origina que en la traducción se pierda lo vernáculo. Incluso, se ha reemplazado la palabra "mishoquitu" (diminutivo de melloco, un tubérculo típico de los Andes) por "potatoes". En esta frase también vemos cómo se pierde el uso del gerundio ("no teniendu") y se reemplaza por "won't have". En el caso de la expresión en quichua, el uso del gerundio indica una acción presente, que se extiende al futuro, mientras que la traducción indica solo una acción futura.

Otra de las tendencias en las que incurre Dulsey es la última que menciona Berman: la supresión de las superposiciones de lenguas. Si cada texto cuenta con una prosa 'polilingüe', en el caso de Huasipungo esto es evidente. Ya hemos visto que en este texto conviven varias lenguas, que dan cuenta, incluso, del nivel social de los personajes. Al suprimir esta superposición, se pierde este plurilingüismo. Esto 
sucede, por ejemplo, en el regaño del mayordomo Policarpio a Andrés cuando se da cuenta de que Cunshi ha muerto. Veamos:

Bien hecho, carajo. Por shugas. Por pendejos. Por animales. ¿Acaso no sé? Comerse la mortecina que el patrón mandó a enterrar. Castigo de Taita Dios. El indio José Risco también está dando botes en la choza... Y la longa Manuela... Antes ellos avisaron pronto. Hasta para ver a la curandera, pes. ¿Y ahora qué haremos? (1953, p. 173)

It's what you deserve, dammit. For being thieves.
And stupid. For being animals. You think I don't
know? You ate up the carcass that the patron
ordered buried. It's a punishment from Taita
Dios. The indian José Risco, too, is writhing in
his hut... And the woman Manuela... But they
said something about it soon enough. In time to
see the curandera, pes. And now what are we
going to do? (1964, p. 77)

Dentro de la prosa de Huasipungo, el habla de los cholos y mestizos, como lo es Policarpio, cuenta con sus particularidades. En el pasaje citado, podemos ver cómo Policarpio utiliza la palabra shugas, que es una adaptación del quichua que quiere decir ladrones, así es como la traduce Dulsey, por "thieves", pero se pierde la superposición de lenguas. Sucede también con usos coloquiales de la variedad andina del español ecuatoriano, como "bien hecho" (traducido por "It's what you deserve"/ "te lo mereces"), "dando botes" ("writhing"/ "retorcerse") o "longa" ("woman"/"mujer"). En la primera frase de la respuesta de Andrés a este regaño también vemos cómo la traducción, al suprimir la superposición de lenguas, homogeniza el texto:

\begin{tabular}{|l|l|}
\hline $\begin{array}{l}\text { Ahura. Uuu... Amitu mayordomu... (1953, p. } \\
\text { 174) }\end{array}$ & $\begin{array}{l}\text { Not now. Oo-oo friend mayordomo... (1964, } \\
\text { p. 178) }\end{array}$
\end{tabular}

En primer lugar, la expresión "ahura" del inicio plantea una duda, la incertidumbre que genera el dolor en Andrés, pero la traducción "not now" se refiere a un ruego, para que no se hable de eso en ese momento tan triste. Así mismo, al traducir "amitu mayordomu" por "friend mayordomo", se pierde el sentido de súplica y se ubica a Andrés en el mismo nivel que Policarpio, cuando no es así. No es lo mismo un amo que un amigo.

Por último, otras deformaciones que me parece importante anotar son las que Berman denomina "destrucción de los ritmos" y "destrucción de los sistematismos". La sonoridad de la lengua con la que se expresa Andrés Chiliquinga en el chasquibay de Cunshi es fundamental para entender el dolor del personaje ante la pérdida. En este lamento proliferan los diminutivos, las repeticiones, los quichuismos, sin embargo, esta sonoridad se pierde en la traducción. El ritmo doloroso del lamento no queda claro en la traducción al inglés, así como los sistemas del quichua. Esto 
sucede, por ejemplo, en la supresión ya mencionada de "sha", al eliminar los diminutivos o al traducir las palabras del quichua.

En este aspecto, también me parece que se destruye el sistema del quichua al cambiar la palabra "chasquibay" por "wake", en el siguiente fragmento:

\begin{tabular}{|l|l|}
\hline - El chasquibay de la pobre Cunshi -opinaron & "The wake of por Cunshi," said the farmers \\
santiguándose los campesinos que de lejos & crossing themselves when from afar they heard \\
pudieron oír aquel murmullo doloroso que se & that grieving murmur which flowed over the \\
esparcía por la ladera en mancha viscosa de luto. & hillside in a viscous blob of mourning. \\
- El chasquibay que aplaca. & "The wake thar shootes." \\
- El chasquibay que despide. & "The wake that says goodbye." \\
- El chasquibaaay. $(1953,177)$ & "The chasquibaaay." $(1964,181)$ \\
\hline
\end{tabular}

El chasquibay es una costumbre quichua de lamentarse ante la pérdida del difunto. Este lamento lo llevan a cabo los parientes cercanos, al ritmo de música popular. El ritual es parte del velorio, pero no constituye la totalidad de este, como sugiere la traducción de Dulsey. Por lo tanto, resulta insuficiente usar la palabra 'wake'.

\section{CONCLUSIONES}

Como hemos visto en este breve análisis, la dificultad más grande para el traductor al inglés de la versión de 1953 de Huasipungo, Bernard Dulsey, ha sido la integración del quichua y la cultura de los indígenas dentro de su traducción. Las estrategias que ha usado Dulsey han sido, en algunos casos, apropiadas, como en la inclusión de un glosario o explicaciones en la traducción. También, una ventaja del traductor ha sido su conocimiento de la cultura andina y la relación estrecha que mantuvo con Jorge Icaza durante la traducción del texto.

No obstante, dentro de la traducción han ocurrido varias deformaciones que han quitado el valor importantísimo que el habla indígena tiene en el texto. Si bien la traducción de Dulsey cuenta con cierto "sabor andino", en el momento de traducir se pierden muchos rasgos propios del habla indígena, como el uso de diminutivos, los cambios en la pronunciación o la inclusión de palabras quichuas. Esto, de alguna forma, 'silencia' la voz indígena y homogeniza la prosa.

Sin embargo, por otro lado, es innegable el aporte de la traducción de Dulsey a la difusión del texto más importante de la literatura ecuatoriana. 


\section{REFERENCIAS BIBLIOGRÁFICAS}

BERMAN, A. (1999). La analítica de la traducción y la sistemática de la deformación, en La traduction et la lettre ou l'auberge du lointain, trad. Julia Fidalgo. París: Seuil, pp. 49-68.

CARO, O. (1995). Las traducciones de las obras de Jorge Icaza al francés Kipus. v. 4, pp. 115-123.

CATFORD, J.C. (1965). A Linguistic Theory of Translation. Oxford: Oxford University Press.

CUEVA, A. (1978). En pos de la historicidad perdida (Contribución al debate sobre la literatura indigenista del Ecuador) Revista de Crítica Literaria Latinoamericana. v. 7/8, pp. 23-28. Centro de Estudios Literarios Antonio Cornejo Polar.

DULSEY, B. (1961). Jorge Icaza and His Ecuador Hispania. vol. 4, n 1, pp. 99-102. American Association of Teachers of Spanish and Portuguese.

FABJAŃSKA-POTAPCZUK, B. (2015). El concepto del indigenismo y las dificultades en la traducción al idioma polaco ZNUV. v. 39, pp. 72-82.

ICAZA, J. (1953). Huasipungo. Bogotá: Losada.

ICAZA, J. (1964). The Villagers (Huasipungo). Trad. Bernard Dulsey. Carbondale: Southern Illinois University Press.

ICAZA, J. (s.f.). Huasipungo. s.1.

LARSON, R. (1965). La evolución textual de Huasipungo de Jorge Icaza Revista Hispanoamericana, pp. 209-222.

MAFLA, C. (2004). Arí-sí-yes. Análisis lingüístico y evaluación de las traducciones de Huasipungo al inglés. Quito: Abya Yala.

ROMANO SUED, S. (2011). Exilio, diáspora y traducción: Paul Zech y la versión alemana de Huasipungo de Jorge Icaza Anuario del Colegio de Estudios Latinoamericanos 2008-2009, pp. $137-150$.

SACOTO, A. (1991). Jorge Icaza: El indigenismo ecuatoriano Revista de Crítica Literaria Latinoamericana. v. 33, pp. 253-259. Centro de Estudios Literarios Antonio Cornejo Polar. 
SPOTURNO, M. L. (2013). El problema de las variedades lingüísticas en la traducción al español de la literatura latina de Estados Unidos: El caso de Julia Álvarez y de Sandra Cisneros Lenguas Vivas. v. 10, pp. 18-29. Instituto de Enseñanza Superior en Lenguas Vivas Juan Ramón Fernández.

TOURY, G. (1995). La naturaleza y el papel de las normas en la traducción. En: Iglesias Santos, M. (coord.), Teoría de los polisistemas, coordinado por Monserrat Iglesias Santos. España: Arco Libros, pp. 233-256.

VETRANO, A. (1974). La problemática psico-social y su correlación linguística en las novelas de Jorge Icaza. Miami: Ediciones Universal. 


\section{ANEXO}

\begin{tabular}{|c|c|}
\hline & \\
\hline $\begin{array}{l}\text { - Ay Cunshi, sha. } \\
\text { - Ay bonitica, sha. } \\
\text { - ¿Quién ha de cuidar, pes, puerquitus? } \\
\text { - ¿Pur qué te vais sin shevar cuicitu? } \\
\text { - Ay Cunshi, sha. } \\
\text { - Ay bonitica, sha. } \\
\text { - Soliticu dejándome, nu. } \\
\text { - ¿Quién ha de sembrar, pes, en huasipungo? } \\
\text { - ¿Quién ha de cuidar, pes, al guagua? } \\
\text { - Guagua soliticu. Ayayay... Ayayay. } \\
\text { - Vamus cuger hierbita para cuy. } \\
\text { - Vamus cuger leñita en munte. } \\
\text { - Vamus cainar en río para lavar patas. } \\
\text { - Ay Cunshi, sha. } \\
\text { - Ay bonitica, sha. } \\
\text { - ¿Quién ha de ver, pes, si gashinita está con } \\
\text { güeybo? } \\
\text { - ¿Quién ha de calentar, pes, mazamurra? } \\
\text { - ¿Quién ha de prender, pes, fogún en noche } \\
\text { fría? } \\
\text { - Ay Cunshi, sha. } \\
\text { - Ay bonitica, sha. } \\
\text { - Pur qué dejándome soliticu. } \\
\text { - Guagua tan shorando está. } \\
\text { - Ashcu tan shorando está. } \\
\text { - Huaira tan shorando está. } \\
\text { - Sembrando de maicitu tan quejando está. } \\
\text { - Monte tan oscuro, oscuro está. } \\
\text { - Río tan shorando está. } \\
\text { - Ay Cunshi, sha. } \\
\text { - Ay bonitica, sha. } \\
\text { - Ya no teniendu taiticu Andrés ni maicitu, ni } \\
\text { - mishoquito, ni zambitu. } \\
\text { - Nada, pes, porque ya nu has de sembrar vus. } \\
\text { - Porque ya nu has de cuidar vus. } \\
\text { - Porque ya nu has de calentar vus. } \\
\text { - Ay Cunshi, sha. } \\
\text { - Ay bonitica, sha. } \\
\text { - Cuando hambre tan cun quien para shorar. } \\
\text { - Cuando dulur tan cun quien para quejar. } \\
\text { - Cuando trabajo tan cun quien para sudar. } \\
\text { - Ay Cunshi, sha. } \\
\text { - Ay bonitica, sha. }\end{array}$ & $\begin{array}{l}\text { - Ay, Cunshi, sha - gone forever. } \\
\text { - Ay, bonitica - lovely one, gone forever. } \\
\text { - Who'll take care of our little pigs, pes? } \\
\text { - Why did you go away like this, without taking } \\
\text { the little guinea pig? } \\
\text { - Ay, Cunshi, gone forever. } \\
\text { - Ay, bonitica, gone forever. } \\
\text { - You left me all alone, didn't you? } \\
\text { - Who'll do the sowing, pes, in our huasipungo? } \\
\text { - Who'll take care, pes, of our little boy? } \\
\text { - Our little boy is all alone. Ayayay... Ayayay... } \\
\text { - Let's get some grass for the guinea pig. } \\
\text { - Let's gather some firewood on the mountain. } \\
\text { - Let's spend some time in the river washing our } \\
\text { feet. } \\
\text { - Ay, Cunshi, gone forever. } \\
\text { - Ay, bonitica, gone forever. } \\
\text { - Who'll see, pes, if the little hen's laid an egg? } \\
\text { - Who'll warm up, pes, our corn porridge? } \\
\text { - Who'll start a fire, pes, on a cold night? } \\
\text { - Ay, Cunshi, gone forever. } \\
\text { - Ay, bonitica, gone forever. } \\
\text { - Why've you left me all alone? } \\
\text { - The little boy's crying, too. } \\
\text { - The dog is crying, too. } \\
\text { - The wind is howling, too. } \\
\text { - Even the little cornfield is weeping. } \\
\text { - The mountain is dark, too. Oh, so dark. } \\
\text { - The river, too, is crying. } \\
\text { - Ay, Cunshi, gone forever. } \\
\text { - Ay, bonitica, gone forever. } \\
\text { - Taitucu Andrés won't have no more corn, no } \\
\text { more potatoes, no more pumpkins. } \\
\text { - Won't have nothing, pes, 'cause you won't sow } \\
\text { - no more. } \\
\text { - Because you won't look after us anymore. } \\
\text { - Ay, Cunshi, gone forever. } \\
\text { - Ay, bonitica, gone forever. } \\
\text { - And when we're hungry, who'll listen to our } \\
\text { - rene're hurting, who'll look after our } \\
\text { - }\end{array}$ \\
\hline
\end{tabular}




\begin{tabular}{|l|l|}
\hline - Donde quiera conseguir para darte postura & $\begin{array}{l}\text { - And when there's a work to do, who'll sweat } \\
\text { nueva. }\end{array}$ \\
with us? \\
- Anacu de bayeta. & - Ay, Cunshi, gone forever. \\
- Rebozu coloradu. & - Ay, bonitica, gone forever. \\
- Tupushina blanca. & - Where can I go to get your new clothes? \\
- cPur qué te vais sin despedir? Comu ashcu sin & - A franel skirt. \\
dueño. & - A red shawl. \\
- Otros añus que vengan tan, guañucta hemus & - A bright kerchief. \\
de cumer. & - Why did you leave without saying goodbye? \\
- Este año ca, Taita Diositu castigandu. & Like a stray dog. \\
- Muriendo de hambre estabas, pes. Peru casha- & - And in years to come, we'll have plenty to eat. \\
du, cashadu. & - But this year Taita Diositu is punishing us. \\
- Ay Cunshi, sha. & - You were dying of hunger, pes, but you said \\
- Ay bonitica, sha. (1953, 175-176). & nothing, nothing. \\
& - Ay, Cunshi, gone forever. \\
& - Ay, bonitica, gone forever. (1964, 178-180) \\
\hline
\end{tabular}

Recebido: 05/02/2018

Aceito: 25/02/2018 